\title{
Detection of Rodent Coronaviruses in Tissues and Cell Cultures by Using Polymerase Chain Reaction
}

\author{
FELIX R. HOMBERGER,* ABIGAIL L. SMITH, AND STEPHEN W. BARTHOLD \\ Section of Comparative Medicine, Yale University School of Medicine, \\ New Haven, Connecticut 06510
}

Received 18 June 1991/Accepted 25 September 1991

\begin{abstract}
A polymerase chain reaction (PCR) method was developed for the detection of rodent coronaviruses in biological material by using reverse transcriptase and two primers which flanked an $M$ gene sequence of 375 bp. PCR detected all of 11 different strains of mouse hepatitis virus (MHV) as well as rat sialodacryoadenitis virus but not bovine coronavirus or human coronavirus strains $\mathrm{OC43}$ and 229E. The $M$ gene sequences of bovine coronavirus and human coronavirus $\mathrm{OC43}$ are homologous to that of $\mathrm{MHV}$, but minor differences exist in the primer regions, preventing annealing of the primers. For detecting MHV-Y in tissue samples, PCR was faster than and at least as sensitive as either of the two bioassays (infant mouse bioassay and mouse antibody production test) currently used for MHV diagnostic purposes.
\end{abstract}

The coronavirus mouse hepatitis virus (MHV) is a common and highly contagious natural pathogen of the laboratory mouse. It can be distinguished antigenically into many strains with different biologies and tissue tropisms (3). Because of its ubiquity, infectivity, and varied effects, MHV has great potential to interfere with biomedical research in a number of ways (4). Epizootic MHV infections can cause overt disease with a wide variety of signs (19). Enzootically infected mice may show no apparent disease but have significantly modified immune and macrophage functions (3, 4). Biological material, such as hybridomas, transplantable tumors, and cell lines, can be contaminated with MHV. The biological properties of infected cells, the transplantability of tumors (1), or the susceptibility of cell lines to other viruses (22) can be modified by MHV contamination. Furthermore, MHV-contaminated biological material can serve as a source of infection for naive mouse colonies.

Due to the wide range of tissue tropism of different MHV strains, the detection of MHV in tissues and cell cultures has always been a problem. Some strains, particularly enterotropic strains, grow almost exclusively in only one cell type $(5,8)$. Cell culture is inefficient for the isolation of $\mathrm{MHV}$ from suspected tissues. Currently, the most sensitive methods to detect MHV are the expensive, labor-intensive, and time-consuming mouse bioassay or mouse antibody production (MAP) test (11).

The goal of this work was to develop a simple, rapid, and accurate method that could detect all strains of MHV in biological material. The polymerase chain reaction (PCR) seemed to be a likely candidate. Even though MHV strains vary greatly antigenically in the spike protein $S$, the other two structural proteins are moderately (nucleoprotein $\mathrm{N}$ ) or highly (membrane protein $\mathrm{M}$ ) conserved (12). By choosing primers in the encoding region of protein $M$, which exhibits high sequence homology among different MHV strains, we hoped to be able to detect a wide range of MHV strains.

\section{MATERIALS AND METHODS}

Mice. Inbred BALB/cByJ mice were obtained from Jackson Laboratory (Bar Harbor, Maine), pregnant outbred

\footnotetext{
* Corresponding author.
}

CR1:CD1BR (CD1) mice were obtained from Charles River Breeding Laboratories (Portage, Mich.), and pregnant or weanling outbred Cr:ORL Sencar mice were obtained from the Animal Genetics and Production Branch (National Cancer Institute, Bethesda, Md.). Mice were shipped in filtered containers and were MHV antibody negative upon arrival. They were housed in microisolator cages containing pine shavings and given food and water ad libitum. Adult mice were euthanized with carbon dioxide gas, and pups were euthanized by decapitation.

Viruses. MHV strain 1 (MHV-1), MHV-3, MHV-A59, MHV-JHM, and MHV-S were obtained from the American Type Culture Collection (Rockville, Md.). MHV-1, MHVA59, and MHV-S were in the form of infected $17 \mathrm{Cl1}$ cell lysates. MHV-3 and MHV-JHM were in the form of $10 \%$ infant mouse liver and 5\% infant mouse brain homogenates, respectively. Enterotropic strain MHV-Y was isolated from a natural outbreak by passage in NCTC 1469 cells (7), and MHV-RI was isolated from a nude mouse by passage in CMT-93 cells (8). Both virus strains were maintained by infant mouse passage and were in the form of $10 \%$ infant mouse intestinal homogenates. MHV-wt1 (5) and MHV-wt3 were field isolates of MHV. MHV-wt1 was isolated from the liver of an athymic mouse and was used as a first-passage NCTC 1469 cell lysate. MHV-wt3 was also from an athymic mouse liver and was used without passage (10\% adult mouse liver homogenate). Köln 63 was one of three Tettnang virus isolates (27) and was used as a third-passage NCTC 1469 cell lysate. Sialodacryoadenitis virus (SDAV) strain 681 was isolated from a rat and had undergone multiple passages in infant mouse brain (9). Bovine coronavirus (BCV) strain Mebus was obtained from Kathryn V. Holmes (Uniformed Services University of the Health Sciences, Bethesda, Md.) and was passaged in human rectal carcinoma cell line HRT 18 (15). Human coronaviruses (HCV) OC43 and 229E were obtained from the American Type Culture Collection in the form of $20 \%$ infant mouse brain homogenate and WI38 cell lysate, respectively, and were used without passage.

Psoralen inactivation of MHV-JHM was accomplished by adding $4^{\prime}$-aminomethyl-4,5',8-trimethylpsoralen hydrochloride (HRI Associates Inc, Emeryville, Calif.) at a final concentration of $10 \mu \mathrm{g} / \mathrm{ml}$ to a $5 \%$ infected mouse brain suspension. The mixture was exposed for $3 \mathrm{~min}$ (minimum 


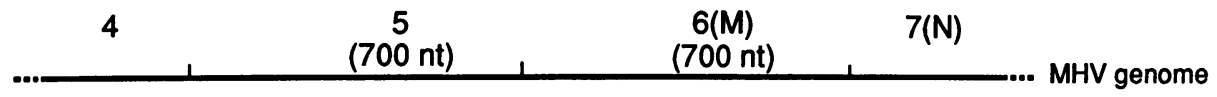

(1800 bp)

\section{(375 bp)}

FIG. 1. Position and length of clone g344 and the sequence amplified by PCR in relation to the MHV genome (gene 6, membrane protein gene). nt, nucleotide.

time for complete inactivation) with constant agitation on a UV transilluminator (model TL33; UVP Inc, San Gabriel, Calif.) to long-wave UV light $(365 \mathrm{~nm}$, average intensity of $7,000 \mu \mathrm{W} / \mathrm{cm}^{2}$ ), as described previously (14). Inactivation of infectivity was confirmed by intracerebral inoculation of treated material, without dilution, into neonatal Sencar mice.

PCR. Primers for PCR were chosen from the region of the MHV genome that encodes the membrane (M) protein, the most conserved structural protein among antigenically distinct strains (12). The two primers 5'-AATGGAACTTC TCGTTGGG-3' and 5'-TAGTGGCTGTTAGTGTATGG-3' flanked a genome fragment $375 \mathrm{bp}$ in length (including the primers) (Fig. 1), containing among others a HaeIII and a $K p l I$ restriction site. A comparison of the sequenced genes for protein M of MHV-A59 (2) and MHV-JHM (23) showed that only 8 nucleotides within the target fragment and none within the primer regions were different.

Cell culture lysates and tissue homogenates were first treated with an RNase inhibitor (40 U of RNasin [Promega, Madison, Wis.] per $100 \mu \mathrm{l})$. RNA was then extracted by sodium dodecyl sulfate (SDS) treatment followed by phenol extraction and ethanol precipitation (24). Single-stranded cDNA was synthesized with avian reverse transcriptase (Promega) at $\mathrm{pH} 8.4$ and $42^{\circ} \mathrm{C}(25)$ with oligo(dT) ${ }_{12-18}$ (Pharmacia LKB Biotechnology Inc., Piscataway, N.J.) as a primer. PCR was performed using Taq polymerase (Boehringer Mannheim Biochemicals, Indianapolis, Ind.) for 30 cycles in a thermal cycler (TCX15; Ericomp Inc., San Diego, Calif.). Each cycle consisted of $30 \mathrm{~s}$ at $95^{\circ} \mathrm{C}, 30 \mathrm{~s}$ at $55^{\circ} \mathrm{C}$, and $1 \mathrm{~min}$ at $72^{\circ} \mathrm{C}$. The last cycle was followed by a 5 -min extension period at $72^{\circ} \mathrm{C}$ and refrigeration at $6^{\circ} \mathrm{C}$. PCR products were electrophoresed on a $0.8 \%$ agarose minigel, stained with ethidium bromide, and visualized under UV light. Selected samples were also evaluated by dot blot hybridization.

Dot blot hybridization. RNA was phenol extracted and ethanol precipitated from pulverized, frozen tissues as described elsewhere (20) except that $5 \mu$ l of diethyl pyrocarbonate per $\mathrm{ml}$ was added to the buffer $(0.3 \mathrm{M}$ sodium acetate, pH 5.0, 5 mM EDTA, 0.5\% SDS). Extracted RNA was denatured with formamide-formaldehyde (25) and dotted on a dry nitrocellulose filter by using a Bio-Dot microfiltration apparatus (Bio-Rad Laboratories, Richmond, Calif.). DNA from PCR was dotted onto nitrocellulose and then denatured with sodium hydroxide. Filters were air dried and baked for $2 \mathrm{~h}$ at $80^{\circ} \mathrm{C}$.

MHV-A59 cDNA clone g344 (10), provided by Susan R. Weiss, University of Pennsylvania, was $\left[{ }^{32} \mathrm{P}\right] \mathrm{dCTP}$ labeled $\left(5 \times 10^{5} \mathrm{cpm} / \mathrm{ml}\right.$ of hybridization buffer) with a random primer kit (Bethesda Research Laboratories, Gaithersburg,
Md.) and used as probe to detect MHV RNA or cDNA. Nitrocellulose filters were hybridized and washed under high stringency at $65^{\circ} \mathrm{C}$ (16) and exposed to X-ray film (Kodak XAR-5; Eastman Kodak Co., Rochester, N.Y.) with an intensifying screen at $-70^{\circ} \mathrm{C}$.

Infant mouse bioassay. For the infant mouse bioassay, four neonatal CD1 mice per sample were inoculated orally with tissue homogenates derived from MHV-Y-infected mice. Mice were sacrificed $48 \mathrm{~h}$ after inoculation, and the ascending colon was collected and fixed in $10 \%$ neutral-buffered formalin ( $\mathrm{pH}$ 7.2). Tissues were embedded in paraffin, sectioned at $5 \mu \mathrm{m}$, stained with hematoxylin and eosin, and examined microscopically for pathognomonic MHV syncytia and colitis.

MAP test. For the MAP test, 4-week-old female Sencar mice were inoculated by the combined oral, intranasal, and intraperitoneal routes with tissue homogenates (three animals per sample) (11). Sentinel animals from the same shipment were housed in separate cages at the bottom of the animal holding rack. All mice were sacrificed for blood collection 2 weeks after inoculation. The resulting sera were diluted 1:10 and screened for MHV antibody by an indirect immunofluorescence assay (26).

\section{RESULTS}

To test the ability of the chosen primers to detect different strains of $\mathrm{MHV}$ and other coronaviruses in a variety of biological materials, PCR was performed on stocks of MHV prototype strains 1, 3, A59, JHM, and S; enterotropic strains MHV-Y and MHV-RI; MHV wild-type isolates wt1, wt3, and Köln 63; and SDAV, BCV, and HCV OC43 and 229E. Psoralen-inactivated MHV-JHM and saline were used as controls and were always handled last throughout RNA extraction, cDNA synthesis, and PCR amplification. All MHV prototype strains and wild-type isolates tested could be detected by amplification with PCR (Fig. 2). In addition, the sample containing SDAV was positive (Fig. 2, lane 13). HCV OC43 and 229E (Fig. 2, lanes 14 and 15) and BCV (data not shown) were not amplified with the MHV primers. The psoralen-inactivated MHV-JHM and the saline control were both negative (Fig. 2, lanes 3 and 16). These findings were confirmed by dot blot hybridization (Fig. 3).

PCR was compared with dot blot hybridization and bioassay methods, including the infant mouse bioassay and MAP test. Twenty-one BALB/c mice were inoculated orally with $10 \mu \mathrm{l}$ of 10 -fold dilutions of enterotropic MHV-Y stock virus (three animals per dilution) or mock inoculated (three animals) and necropsied $48 \mathrm{~h}$ later. The ascending colon was collected, and half of it was placed in an RNase-free tube, snap frozen in liquid nitrogen, and stored at $-70^{\circ} \mathrm{C}$ to be 


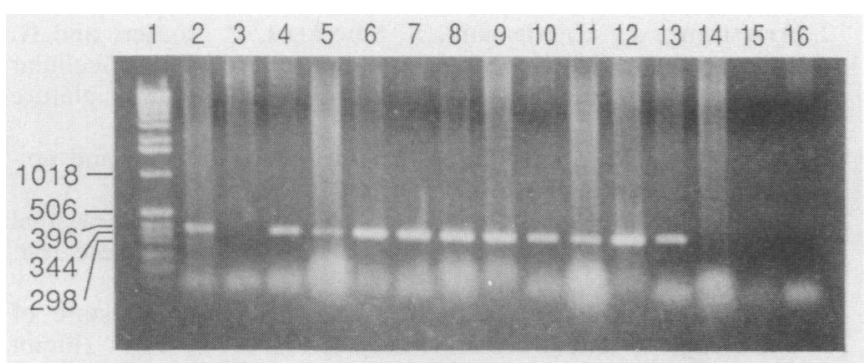

FIG. 2. Ethidium bromide-stained $0.8 \%$ agarose minigel with PCR amplification products of different coronavirus preparations. Lane 1, markers in base pairs; lane 2, MHV-JHM; lane 3, psoraleninactivated MHV-JHM; lane 4, MHV-S; lane 5, MHV-3; lane 6, MHV-1; lane 7, MHV-A59; lane 8, MHV-Y; lane 9, MHV-RI; lane 10, MHV-wt1; lane 11, MHV-wt3; lane 12, MHV Köln 63; lane 13, SDAV; lane 14, HCV OC43; lane 15, HCV 229E; lane 16, negative control (saline).

used for dot blot hybridization. The other half was homogenized in medium as described previously (6) and was used for PCR, mouse bioassay, and the MAP test. In all mice inoculated with $10^{4}$ to $10^{6} 50 \%$ infective doses of MHV-Y and in two of three mice inoculated with $10^{3} 50 \%$ infective doses, MHV RNA could be detected in the ascending colon by PCR. Tissue samples from the other animals, including the controls, were negative. Dot blot hybridization and the MAP test yielded the same results, but infant mouse bioassay detected MHV in only nine samples (Table 1).

To compare the sensitivities of the different methods, four positive samples were selected from the groups inoculated with $10^{5}$ and $10^{6} 50 \%$ infective doses of MHV-Y (samples 1 , 2,4 , and 5). Tenfold dilutions of the homogenized ascending colons were made in saline, and each dilution was tested by PCR, infant mouse bioassay, and the MAP test. Dot blot hybridization was not used in this comparison. All four samples were PCR positive up to the dilution $10^{-4}$ and infant mouse bioassay positive up to the dilution $10^{-3}$ (Table 2). The highest dilution positive in the MAP test was identical to that in PCR for two samples (1 and 4) and $1 \log _{10}$ lower for the other two samples (2 and 5) (Table 2).

\section{DISCUSSION}

MHV can be differentiated into a number of antigenically distinct strains by serum neutralization testing, but all strains

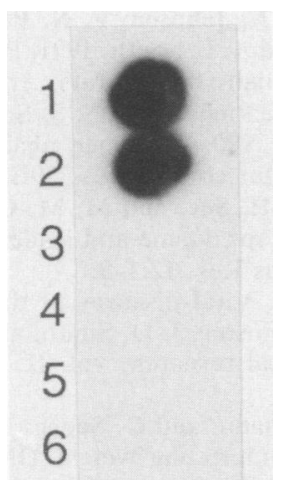

FIG. 3. Dot blot of PCR amplification products hybridized with ${ }^{32}$ P-labeled clone g344. 1, MHV-JHM; 2, SDAV; 3, BCV; 4, HCV OC43; 5, HCV 229E; 6, negative control (saline).
TABLE 1. Comparison of four different assays to detect MHV in ascending colon of adult BALB/c mice experimentally infected with different doses of MHV-Y

\begin{tabular}{lccccc}
\hline & & \multicolumn{4}{c}{ Result of: } \\
\cline { 3 - 6 } $\begin{array}{c}\text { Sample } \\
\text { no. }\end{array}$ & $\begin{array}{l}\text { Virus } \\
\text { dose }\end{array}$ & PCR & $\begin{array}{l}\text { Dot blot } \\
\text { hybrid- } \\
\text { ization }\end{array}$ & $\begin{array}{c}\text { Infant } \\
\text { mouse } \\
\text { bioassay }\end{array}$ & $\begin{array}{c}\text { MAP } \\
\text { test }\end{array}$ \\
\hline $1-3$ & $10^{6}$ & + & + & + & + \\
$4-6$ & $10^{5}$ & + & + & + & + \\
$7-8$ & $10^{4}$ & + & + & + & + \\
9 & $10^{4}$ & + & + & - & + \\
10 & $10^{3}$ & + & + & - & + \\
11 & $10^{3}$ & + & + & + & + \\
12 & $10^{3}$ & - & - & - & - \\
$13-15$ & $10^{2}$ & - & - & - & - \\
$16-18$ & $10^{1}$ & - & - & - & - \\
$19-21$ & 0 & - & - & - & - \\
\hline
\end{tabular}

${ }^{a}$ Neonatal mouse $50 \%$ infective dose; samples 19 to 21 were mockinfected.

share common antigens and have high sequence homology in parts of their genome. By choosing PCR primers in the encoding region of structural protein $\mathrm{M}$, a highly conserved section of the viral RNA, we were able to recognize all of 11 different strains of $\mathrm{MHV}$, both prototype and wild-type isolates. Coronaviruses can be differentiated into several antigenic groups. MHV, SDAV, BCV, and HCV OC43 belong to one, while HCV $229 \mathrm{E}$ belongs to a separate group. That the MHV primers were able to detect SDAV underscores the close relationship between coronaviruses of mouse and rat origin. BCV and HCV OC43 could not be amplified even though they belong to the antigenic group containing MHV. These viruses share a high degree of homology with $\mathrm{MHV}$, but comparison of the BCV genome sequence (21) with the MHV primers showed two and five mismatches. With five mismatches, the second primer was sufficiently different to prevent annealing. The $\mathbf{M}$ gene of

TABLE 2. Sensitivity of PCR relative to that of two bioassays for detection of MHV in serial 10-fold dilutions of intestinal homogenate from adult BALB/c mice inoculated wtih MHV-Y

\begin{tabular}{|c|c|c|c|c|}
\hline \multirow{2}{*}{$\begin{array}{c}\text { Sample } \\
\text { no. }\end{array}$} & \multirow[b]{2}{*}{ Dilution } & \multicolumn{3}{|c|}{ Result of: } \\
\hline & & PCR & $\begin{array}{l}\text { Infant mouse } \\
\text { bioassay }\end{array}$ & $\begin{array}{c}\text { MAP } \\
\text { test }\end{array}$ \\
\hline \multirow[t]{4}{*}{1} & $10^{-2}$ & + & + & + \\
\hline & $10^{-3}$ & + & + & + \\
\hline & $10^{-4}$ & + & - & + \\
\hline & $10^{-5}$ & - & - & - \\
\hline \multirow[t]{4}{*}{2} & $10^{-2}$ & + & + & + \\
\hline & $10^{-3}$ & + & + & + \\
\hline & $10^{-4}$ & + & - & - \\
\hline & $10^{-5}$ & - & - & - \\
\hline \multirow[t]{4}{*}{4} & $10^{-2}$ & + & + & + \\
\hline & $10^{-3}$ & + & + & + \\
\hline & $10^{-4}$ & + & - & + \\
\hline & $10^{-5}$ & - & - & - \\
\hline \multirow[t]{4}{*}{5} & $10^{-2}$ & + & + & + \\
\hline & $10^{-3}$ & + & + & + \\
\hline & $10^{-4}$ & + & - & - \\
\hline & $10^{-5}$ & - & - & - \\
\hline
\end{tabular}


HCV OC43 has not been sequenced yet, but since OC43 and BCV show few sequential differences within the more heterologous encoding region of protein $N(18)$, the $M$ gene sequences of the two viruses can be expected to be very similar. It is not surprising that the target sequence in HCV $229 \mathrm{E}$ could not be amplified, since this virus shares little antigenic homology with MHV. Sequence comparison (17) revealed that primer 1 had five mismatches and the second primer did not match at all. The PCR method described in the present study seems therefore to be specific for the rodent coronaviruses, MHV and SDAV. It could potentially be used to help differentiate human and murine coronaviruses when the origin of an isolate is in question $(10,13,28)$.

A number of different assays have been described for the detection of MHV in biological materials. An in vitro system using cell culture has proven to be highly insensitive and strain specific because of the strict tissue tropism of some strains of MHV $(8,11)$. Therefore, in vivo assays have been generally used. In experimental settings, when the exact strain of MHV is known, infant mouse bioassay with intracerebral, intranasal, or oral inoculation of neonatal mice has been utilized successfully. For diagnostic purposes, when no information about an isolate is available, the MAP test with its broad range of specificity has been used. This study showed that in detecting MHV in infected tissue, PCR was more sensitive than the infant mouse bioassay and at least as sensitive as the MAP test. In addition, PCR results could be generated in less time, generally within a $24-\mathrm{h}$ period. The bioassay requires at least 1 week and the MAP test requires almost 1 month for completion. The actual labor time necessary to process one sample was about the same for all three methods, as were the costs of PCR and infant mouse bioassay. The MAP test was somewhat more expensive. PCR does not need animal holding facilities, histology, or a trained pathologist but can be performed in any lab that has access to a thermal cycler. Finally, general application of PCR will contribute to reduced animal use in biomedical research.

By using enterotropic MHV-Y, we chose the most difficult system for this comparison. Enterotropic MHV strains do not grow well in cell culture, and no sensitive in vitro assay has been described for enterotropic MHV. MHV-Y replicates in the intestine, which contains high levels of RNase (24), rendering extraction of single-stranded RNA very difficult. Successful PCR amplification from this tissue suggests that other organs, tumors, or even cell cultures treated with appropriate care should not pose insurmountable technical problems.

The present study demonstrated that PCR combines the sensitivity of the strain-specific bioassay with the ability of the MAP test to detect all strains of MHV, without the long turnaround time of either method. It appears to be viable as an alternative to the MAP test for detecting MHV contamination of biological material.

\section{ACKNOWLEDGMENTS}

This work was supported by grants RR02039 and RR04507 from the National Center for Research Resources, National Institutes of Health, Bethesda, Md.

We thank Debby Beck, Liz Johnson, and Valerie Flowers for their technical assistance.

\section{REFERENCES}

1. Akimaru, K., G. M. Stuhlmiller, and H. F. Seigler. 1981. Influence of mouse hepatitis virus on the growth of human melanoma in the peritoneal cavity of the athymic mouse. J. Surg. Oncol. 17:327-339.
2. Armstrong, J., H. Niemann, S. Smeekens, P. Rottier, and G. Warren. 1984. Sequence and topology of a model intracellular membrane protein, E1 glycoprotein, from a coronavirus. Nature (London) 308:751-752.

3. Barthold, S. W. 1986. Mouse hepatitis virus biology and epizootiology, p. 571-601. In P. N. Bhatt, R. O. Jacoby, A. C. Morse III, and A. E. New (ed.), Viral and mycoplasmal infection of laboratory rodents: effects on biomedical research. Academic Press, San Diego, Calif.

4. Barthold, S. W. 1986. Research complications and state of knowledge of rodent coronaviruses, p. 53-89. In T. F. Hamm (ed.), Complications of viral and mycoplasmal infections in rodents to toxicology research testing. Hemisphere, Washington, D.C.

5. Barthold, S. W., and A. L. Smith. 1984. Mouse hepatitis virus strain-related patterns of tissue tropism in suckling mice. Arch. Virol. 81:103-112.

6. Barthold, S. W., and A. L. Smith. 1987. Response of genetically susceptible and resistant mice to intranasal inoculation with mouse hepatitis virus. Virus Res. 7:225-239.

7. Barthold, S. W., A. L. Smith, P. F. S. Lord, P. N. Bhatt, R. O. Jacoby, and A. J. Main. 1982. Epizootic coronaviral typhlocolitis in suckling mice. Lab. Anim. Sci. 32:376-383.

8. Barthold, S. W., A. L. Smith, and M. L. Povar. 1985. Enterotropic mouse hepatitis virus infection in nude mice. Lab. Anim. Sci. 35:613-618.

9. Bhatt, P. N., D. H. Percy, and A. M. Jonas. 1972. Characterization of the virus of sialodacryoadenitis of rats: a member of the coronavirus group. J. Infect. Dis. 126:123-130.

10. Budzilowicz, C. J., S. P. Wilczynski, and S. R. Weiss. 1985. Three intergenic regions of coronavirus mouse hepatitis virus strain A59 genome RNA contain a common nucleotide sequence that is homologous to the $3^{\prime}$ end of the viral mRNA leader sequence. J. Virol. 53:834-840.

11. de Souza, M., and A. L. Smith. 1989. Comparison of isolation in cell cultures with conventional and modified mouse antibody production tests for detection of murine viruses. J. Clin. Microbiol. 27:185-187.

12. Fleming, J. O., S. A. Stohlman, R. C. Harmon, M. M. C. Lai, J. A. Frelinger, and L. P. Weiner. 1983. Antigenetic relationships of murine coronaviruses: analysis using monoclonal antibodies to JHM (MHV-4) virus. Virology 131:296-307.

13. Gerdes, J. C., I. Klein, B. L. DeVald, and J. S. Burks. 1981. Coronavirus isolates SK and SD from multiple sclerosis patients are serologically related to murine coronavirus A59 and JHM and human coronavirus OC43, but not to human coronavirus 229E. J. Virol. 38:231-238.

14. Hanson, C. V., J. L. Riggs, and E. H. Lennette. 1978. Photochemical inactivation of DNA and RNA viruses by psoralen derivatives. J. Gen. Virol. 40:345-358.

15. Hogue, B. G., B. King, and D. A. Brian. 1984. Antigenetic relationship among proteins of bovine coronavirus, human respiratory coronavirus $\mathrm{OC} 43$, and mouse hepatitis virus A59. J. Virol. 51:384-388.

16. Jacoby, R. O., E. A. Johnson, F. X. Paturzo, D. J. Gaertner, J. L. Brandsma, and A. L. Smith. 1991. Persistent rat parvovirus infection in individually housed rats. Arch. Virol. 117:193-205.

17. Jouvenne, P., C. D. Richardson, S. S. Schreiber, M. M. C. Lai, and P. J. Talbot. 1990. Sequence analysis of the membrane protein gene of human coronavirus 229E. Virology 174:608-612.

18. Kamahora, T., L. H. Soe, and M. M. C. Lai. 1989. Sequence analysis of nucleocapsid gene and leader RNA of human coronavirus OC43. Virus Res. 12:1-9.

19. Kraft, L. M. 1982. Viral diseases of the digestive system, p. 159-191. In H. L. Foster, J. D. Smith, and J. G. Fox (ed.), The mouse in biomedical research, vol. II. Academic Press, Inc., New York.

20. Krieg, P., E. Amtmann, and G. Sauer. 1983. The simultaneous extraction of high-molecular-weight DNA and of RNA from solid tumors. Anal. Biochem. 134:288-294.

21. Lapps, W., B. G. Hogue, and D. A. Brian. 1987. Sequence analysis of the bovine coronavirus nucleocapsid and matrix protein genes. Virology 157:47-57. 
22. Mizzen, L., S. Cheley, and M. Rao. 1983. Fusion resistance and decreased infectability as major host cell determinants of coronaviruses persistence. Virology 128:407-417.

23. Pfleiderer, M., M. A. Skinner, and S. G. Siddell. 1986. Coronavirus MHV-JHM: nucleotide sequence of the mRNA that encodes the membrane protein. Nucleic Acids Res. 14:6338.

24. Rotbart, H. A. 1990 . PCR amplification of enteroviruses, p. 372-377. In M. A. Innis, D. H. Gelfand, J. J. Sninsky, and T. J. White (ed.), PCR protocols: a guide to methods and applications. Academic Press, San Diego, Calif.

25. Sambrook, J., E. F. Fritsch, and T. Maniatis. 1989. Molecular cloning: a laboratory manual, 2nd ed. Cold Spring Harbor
Laboratory Press, Cold Spring Harbor, N.Y.

26. Smith, A. L. 1983. An immunofluorescence test for the detection of serum antibody to rodent coronaviruses. Lab. Anim. Sci. 33:157-160.

27. Smith, A. L., J. Casal, and A. Main. 1983. Characterization of Tettnang virus: complications caused by passage of the virus in mice from a colony enzootically infected with mouse hepatitis virus. Am. J. Trop. Med. Hyg. 32:1172-1176.

28. Weiss, S. R. 1983. Coronaviruses SD and SK share extensive nucleotide homology with murine coronaviruses MHV-A59, more than that shared between human and murine coronaviruses. Virology 126:669-677. 